\title{
THE ABORIGINAL CHILD AT SCHOOL
}

A National Journal for Teachers of Aborigines

$$
\text { Vol.18 No.3, June/July } 1990
$$

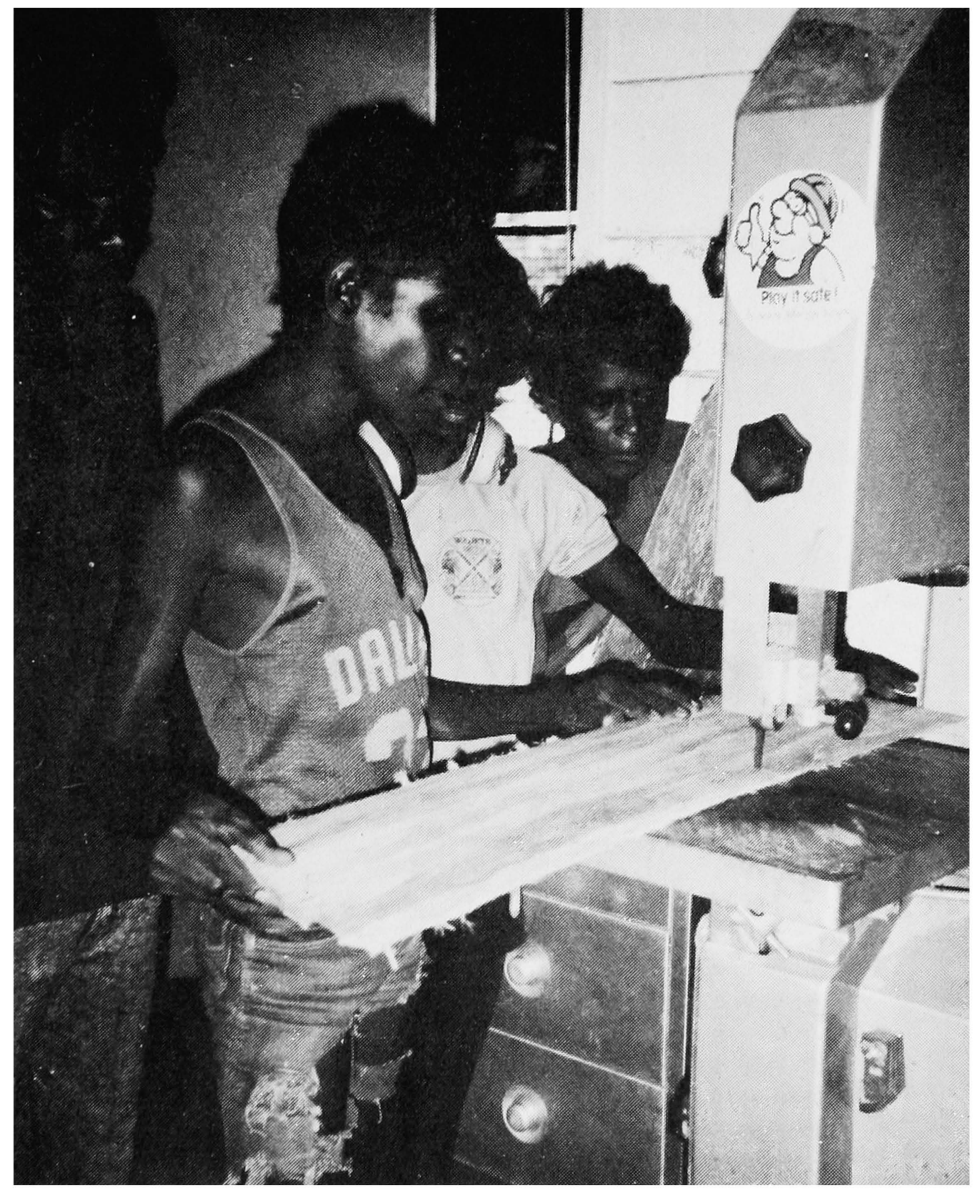


Honorary Editor:

Mrs Dawn Muir

Lecturer, Department of Education

The University of Queensland

St Lucia Qld 4067

Tel (07) $377 \quad 3201 \quad$ Fax $07 \quad 3715107$

Production \&

Distribution:

Mary Hammill Tel. (07) 3772388

Printing:

The University of Queensland Printery

ISSN $0310-5822$

The editor wishes to thank

The Department of Employment, Education and Training for its

financial support in the production of this journal.

Cover photo: Post-primary students at OLSH School, Wadeye, Northern Territory

(Photograph by courtesy of Br B. Graham)

The views expressed in this journal are not necessarily those of the editor.

All material published in this journal is copyright. Reproduction in any form is prohibited except with the express permission of the editor. 


\section{CONTENTS}

Editorial

B. Graham

: The Implications of Statements by

Aboriginal Leaders for Language

Teaching in Aboriginal Schools

Jayne Hodgson : History of Aboriginal Education

Cape York Peninsula : A Case Study

Tricia Lasorsa : An Analysis of the Aboriginal Education 36 Policy Documents of Queensland

Book Review:

Kim Akerman

: The Teaching Stones:

[of the Outcast Tribe]

A very modern myth

Neil Mooney

Lee Casey

Jan Allam

Koorie Primary Study Centre Ulladulla

Cheryle Hughes

Lorraine Carriage:

\section{THE ABORIGINAL CHILD AT SCHOOL \\ Subscription - $\$ 15.00$ \\ See back cover for details}

\section{All correspondence to -}

The Editor

The Aboriginal Child at School

Department of Education

The University of Queensland

St Lucia Qld 4067 